\title{
Retreating Academics: \\ Creating Spaces for the Scholarship of Teaching and Learning
}

\author{
Sue Southwood
}

Rhodes University, South Africa

(Received 2 December 2016; accepted 15 June 2017)

\begin{abstract}
Recognising the struggles many academics experience around academic writing, this paper explores particular spaces created to support academic engagement in the scholarship of teaching and learning: the space of writing retreats. The metaphor of 'tapestry' is used to capture the development of a complex conceptual image of the writing retreats. A metatheoretical framework - a matrix built from the 'warp' and 'weft' of spatiality and sociality supports the development of a pedagogical picture of presence. Analysis of qualitative data, generated through questionnaires and informal group discussions, led to the identification of dimensional 'threads', considered as enabling conditions, for scholarly engagement. Such dimensions speak to spaces not only within (personal) and between people (interpersonal), but also spaces beyond (extrapersonal).
\end{abstract}

Keywords: presence, retreats, scholarship, sociality, spatiality, writing

As academics working in the field of academic development and higher education studies, one of our concerns is to develop scholarship in the field of teaching and learning (SoTL). In doing this, we are not only engaged with our own research and writing but have become increasingly engaged with that of other academics. This paper focuses on the experiences of academics from a range of disciplines, at different stages in their professional journeys, participating in a recent initiative to support engagement with, and the development of, the scholarship of teaching and learning. With the support of the Teaching Development Grant from the Department of Higher Education and Training, the Centre of Higher Education Research Teaching and Learning (CHERTL) at Rhodes University, has, for the past three years, been offering academics writing about various aspects related to teaching and learning regular opportunities to participate in writing retreats.

Drawing on other research around academic writing, we explore the space offered through the retreat and how it supports academics in developing their writing around teaching and learning. Framed theoretically by notions of spatiality and sociality, reflections of participants are analysed here to develop an understanding of the space of the writing retreat and how it contributes to the development of academic writing. A range of experiential 'threads' are identified which 'weave' with others to form a complex space supporting the development of the scholarship of teaching and learning. The findings expressed in this paper Vol.5, No.2 (2017): pp. 16-32 Corresponding author: s.southwood@ru.ac.za doi: $10.14426 /$ cristal.v5i2.86 
indicate that retreating is not about escaping responsibility or just a 'nice to have', but that writing retreats offer a space of multiple dimensions, affording conducive environments for academic engagement with writing. Using a metaphor of 'tapestry', this paper builds an argument for the centring of writing retreats in the academy.

\section{Context}

\section{Writing in Academia}

Writing is central to academic work. We express our ideas, describe our research and create new knowledge in writing. We progress in our careers through writing. We develop our thinking through peer review of our writing. As academics and researchers we 'act' through writing. (Murray, 2015: 13)

Writing is recognised as a central component of academic life. The ability to write well, and develop and maintain a strong publication output, is clearly understood as a fundamental literacy for academic success. However, as Aitchison and Guerin (2014: 3) point out, academic writing is regarded as 'a source of anxiety', and 'a contentious space'. Many academics, they point out, report 'ongoing challenges regarding scholarly writing, not the least of which is a desire for supportive environments within which writing will happen'.

Academic writing is recognised as not being easy. Many academics lack skills and confidence in writing and experience it as 'mysterious, daunting and unsupported' (Moore, Murphy and Murray, 2010 quoted in Castle and Keane, 2016: 73). The multitude of books, blogs and other resources aimed at helping academics to write is testament to the need for support around academic writing. Foci of such resources include a wide range of topics, including styles of writing, finding your own voice, writing for publication, academic integrity, and time management.

As Castle and Keane (2016) point out, even though research and writing may be recognised as important for institutions, specific space and support for these activities is often absent. They argue that there has to be both time set aside to do the research, and a supportive culture for research writing. 'There are many academics', they argue, 'even in researchintensive universities, who do not have access to the opportunities and experiences which could lead them to be productive and successful writers' (Castle and Keane, 2016: 77).

Castle and Keane highlight two main issues which arise from their review of the literature: firstly, the need to affirm the place of research and writing in academia by establishing it as 'business as usual'. Echoing Lee and Boud (2003), they argue that this can be done by building in time and space in planning and policy development. Secondly, they advocate the development of new strategies to support academic writing, and to make it an enjoyable and rewarding endeavour. This, they argue, 'requires initiative and active support from communities of scholars, as well as those entrusted with the professional development of academic staff' (Castle and Keane, 2016: 76).

This paper takes up and explores a response to Castle and Keane's second challenge support - and opens the space to consider how we could use what we learn from such initiatives to address their first challenge, making our writing part of 'business as usual'. Starting with the second challenge in mind, it is clear from previous research (Benvenuti, Castle and Keane, 2013), and feedback from our own colleagues, that despite pressure to 
publish from the academy, many academics struggle to make the time to write in their everyday work schedule. Even where academics are encouraged to set aside regular writing/research days, overwhelmed with teaching, research, administration and both institutional and community engagement, writing is often placed on the back-burner. Inevitably this means writing tends to happen in the breaks, when academics are exhausted and need to take some time off, or when on sabbatical, which happens only periodically.

Adding to the complexity of the situation is that the writing we are speaking to here is that related to the scholarship of teaching and learning (SoTL) - the design, implementation and publication of research around engagement with teaching and learning. For many, this means engagement with a different genre of language, thought and ideas. The majority of academics, though expected to teach as a major part of their academic role, are not educationalists and are therefore not writing in their own field or discipline. This makes what is already for some a difficult task even more challenging. In an effort to address this, the support this paper is focusing on is the space of the writing retreat.

\section{The Writing Retreat}

With the support of the Teaching Development Grant (TDG) from the South African Department of Higher Education and Training (DHET), Rhodes University along with other universities in South Africa, have been able to organise regular writing retreats and extend their reach to the broader academic community.

Previous research argues for the value writing retreats offer to academics to support the development and publication of academic writing. Writing retreats offer spaces of dedicated time and focus encouraging 'depth and flow', can support the development of writing skills (McGrail, Rickard and Jones, 2006 in Castle and Keane, 2016), and increase personal motivation to write (Casey, Baron and Gordon, 2013 in Benvenuti, Castle and Keane, 2013). Academics participate in them because they 'need structured time for writing, want to improve their writing skills, and want to gain motivation, confidence and peer support' (Benvenuti, et al. 2013).

The retreats referred to here have, as mentioned earlier, the extra layer of challenge in that academics are not writing about research in their own discipline, but are writing towards the scholarship of teaching and learning. Most of the participants, however, have already attended courses run by CHERTL in the field of higher education studies, or have had some other forms of engagement with the scholarship of teaching and learning, which inform and influence their writing.

Three times a year, before the academic year begins, and during each swot or study week when there are no lectures, approximately 12 academics from across the university are invited to join 2-3 facilitators from CHERTL to 'retreat' to the mountains roughly two hours' drive from campus to focus on the scholarship of teaching and learning, and write. Application forms make clear that selection of candidates is based on those who are developing a text around the research of teaching and learning, such as a teaching portfolio (for tenure or promotion), or a summative assessment text for a qualification in HE, such as the Postgraduate Diploma in Higher Education (PGDipHE), an MEd, PhD, or a paper for publication. 
The venue at which we hold our retreats, The Edge Mountain Retreat, sits on the precipice of a beautiful valley between the mountains, in the Hogsback area of the Eastern Cape. It is a very special place, offering a beautiful and tranquil environment, a space of both isolation and possible integration, introspection and potential interaction. The venue offers single accommodation in comfortable rooms with space to work alone. We make use of their 'boardroom' for sessions where large groups come together around the table, while others work alone or in small groups in other more flexible areas of the venue. Roaring fires in winter invite you to sit with the cat on the couch or snuggle in bed with your laptop on your knee. When the weather is conducive, the venue also offers a range of spaces outside, on the open stoep, under trees, and by The Labyrinth. The surrounding area offers a range of walks in stunning landscapes, including forests, waterfalls and stunning mountain edge vistas.

The retreat, which began as a two-night sojourn, has now been extended to three nights, in response to feedback from participants wanting more time. We leave early on a Tuesday morning, return late on a Friday afternoon, and try to make the most of the time we have in-between. The retreat is structured around working sessions between meals. These sessions include meetings, personal writing, sharing and feeding back on writing, and engaging with workshops around identified foci.

The retreats may be described as taking a 'hybrid' form (Murray, 2015), where both individual and communal spaces of engagement are offered and taken advantage of. We start and end each retreat with communal meetings, committing to and reflecting on our intentions respectively, sharing struggles and strengths, and planning the way forward. The rest of the space at the retreat is spent focusing on the writing, and participants may work alone or together. While the participants are encouraged to pair up with someone else in the group as a critical friend, to give to each other feedback on their writing, they are also free to share their work with any of the CHERTL facilitators. Over lunch each day we share how things are going and support each other by offering suggestions and advice. In addition to this, resources, such as a selection of books and papers, are brought in by the facilitators, who also offer workshops around writing issues identified by the participants.

The most popular workshop offered has been one focusing on writing strategies, where examples are shared from the literature, but most importantly individuals in the group share their own experiences and the strategies they have developed to help them with academic writing in general, and SoTL in particular. Another popular workshop is on the development of Teaching Portfolios, a particular form of SoTL, which all academics engage in as requisite for processes of securing tenure and promotion. As a form of personal research, these texts often form the basis of a future paper for publication in the field of higher education studies.

\section{Theory}

The theoretical orientation of this work is based around two fundamentally integrated notions: spatiality and sociality. Both of these theoretical constructs focus the pedagogical orientation of writing retreats on the persons involved and the relations between them. This, it could be argued, responds to the call for a 'pedagogy of presence' (Mbembe, 2015), a focus on, awareness of, and a working with, existence. Similar to what Bronack and colleagues refer to as 'presence pedagogy' (Bronack, Sanders, Cheney, Riedl, Tashner and Matzen, 
2008), the orientation adopted here is a way of engaging, grounded in social constructivist theory (Vygotsky, 1978). The concept of presence alludes to the building of communities of practice, and the facilitation of environments which foster collaboration, each member both teacher and learner, learning with and from one another.

Such a pedagogy capitalises on the presence of others, encouraging participants of a learning community to share in the responsibility for encouraging, challenging, and supporting one another. This is based on the recognition that all participants bring with them different experiences and levels of expertise, which can be shared and worked with. Although serendipitous interactions while walking, eating, drinking wine in front of the fire etc, are recognised as vital parts of such environments, spaces are specifically designed to facilitate different forms of engagement - within oneself, between oneself and others, and beyond.

Echoing Bronack et al. (2008: 64), such an orientation is based on the understanding that 'learning does not occur in isolation, but happens in concert with others through mediated interaction'. The writing retreats are designed to encourage not only spaces of personal contemplation and construction, but also interaction and collaboration among participants. Multiple spaces offer different opportunities for interaction and engagement: formal communal meetings at the start and end of the retreats, informal meetings over lunch, workshops around specific aspects of writing, engagement with critical partners and facilitators, even informal chats on evening walks or morning labyrinthal contemplations. Such diverse spaces of engagement, whether planned or serendipitous, are recognised as integral aspects of the retreats.

\section{Spatiality}

The interest in spatiality is informed by a turn towards reimagining the conceptualisation of space in the academy. The notion of space has 'escaped the confines of the discipline of geography' (Arias, 2010: 29) and is now invoked in an effort to understand broad social processes. Space, is viewed here as a universal medium, 'neither as a container nor as an abstract construct, but as the general framework for human exchange' (Kümin and Usborne, 2013: 316). As Arias (2010: 29) points out 'the social production of spatiality.... offers a rich opportunity to facilitate interdisciplinary dialogues'. Similarly to Arias' work, this study demonstrates how multidisciplinary scholarship, in this case around teaching and learning, can be facilitated. This study draws on postcolonial interpretations of space as a negotiated set of situated practices, which both transgress and connect.

The thinking here around the academic experience of writing retreats is informed theoretically by a notion of spatiality in which 'space' is understood as a 'dimension of social relations and imaginations...not an objective structure but rather a social experience. It is about social practises, the way people engage with the world. It is a social construct...constituted by, as well as constitutive of, social relations and social practices' (Baerenholdt and Simonsen, 2004: 1-2). Drawing on a relational orientation to spatiality, space is given meaning through human agency.

Space is therefore not only regarded as physical or temporal conditions beyond the person, but more fundamentally in relation to a notion of space within and between persons. This spatial orientation signals a conceptual move away from space as objective absolute to 'space as process and in process' (Baerenholdt and Simonsen, 2004: 8). Such a conception of 
spatiality is not about stasis or absence of temporality, but rather about constantly being in the process of development, the continuing juxtaposition and movement within, between and beyond persons with ideas in context.

The notion of spatiality, and the idea of working in the spaces within, between and beyond people, forms the 'warp' of the fundamental frame holding the conceptual 'weave' of the study.

\section{Sociality}

The theoretical approach adopted may also be viewed as a 'social practice' approach (Kemmis, 2005; Schatzki, 2001), where the development of academic writing is viewed as a social endeavour in which writing and knowledge-creation are regarded as integral to each other, in the company of others. The term 'company' here is not confined to the physical company we have with others, e.g. at writing retreats, but extends to the work of other writers we choose to draw on in our journey.

While the orientation to writing in this text is profoundly social, it is also deeply embedded in practice. Drawing from Aitchison and Guerin (2014: 9), writing is positioned at the "nexus of the social and practice...enabling a reconsideration of scholarly writing and writers as socio-material phenomena shaped by the mutually constitutive influences of embodied relational practices'. The duality of the social and the practice come together in the particular context of the writing retreat, towards a shared social practice of writing for the purposes of advancing the scholarship of teaching and learning.

It is recognised, however, that such engagement stands in opposition to the traditionally 'individualistic ethos of higher education' (Murray, 2015: 17). As Murray points out, academic writing is often portrayed as a 'secret act' in that academics not easily share and discuss their writing practices' (Murray, 2015: xiii). Murray speaks to the paradox of writing in that it is a social act, drawing on the world around us and other work in the field, yet in academia it is not something that is often discussed or engaged with overtly in spaces with others. The act of writing is rather invisible, 'hidden', done in isolation - an expected and central activity of an academic which has no formal spaces of development or support in engagement with others: 'a social process which is practiced without the use of social processes' (ibid: 2). The lack of such processes can contribute to making academic writing a more mysterious and challenging activity than it need be, inhibiting scholarly engagement and particularly the sharing of it with others through publication.

Writing retreats offer spaces of writing in community with others. While studies (Grant, 2006; Grant and Knowles, 2000; Moore, 2003; Murray and Newton, 2009) have demonstrated the positive influence writing retreats have on writers and researchers at all stages of their career, the key mechanism, Murray (2015: 63) argues, is the 'presence of and interactions with other writers'. Murray's research shows that it is not just about having the dedicated space and time of the writing retreat that is important, but that the presence of other writers committed to writing and the discussion of writing with them, are also strongly influential. Going beyond notions of temporal and physical space, Murray (2015) suggests the central importance of the relationships. 
The notion of sociality forms the 'weft' of the fundamental frame holding the conceptual 'weave' of study. Together, theories of socio-spatiality underpin the work shared here.

\section{Methodology}

The methodology of this research may be identified as situated along Somerville's (2007) continuum of 'postmodern emergence'. Fundamental to the notion of emergence is the idea of the liminal - the space between. As Somerville (2007: 239) points out, 'the liminal is theorised as a critical time and space for emergence.... It is about entering a particular space of creation'. The focus is on creation of meaning from the relationship between the parts. These creations are 'naïve in the sense that they are produced and valued in and of the moment, a pause in an iterative process of representation, engagement and reflexivity' (Somerville, 2007: 239).

The data drawn on for this study was gathered through the generation of feedback on the experience of the retreats. Evaluation questionnaires were completed at the end of each retreat by each of the participants, followed by the capturing of informal focus group discussions. Such participant reflection on the individual experiences of the writing retreats can be regarded as a 'pause' (Richardson, 1994), a 'relational artefact' (a term used by Somerville (2007) and understood to mean an object representing social engagement) of the interaction between the researcher and the other retreat participants. The reflections retain their own integrity in the pause, but are interpreted through iterative processes of representation, engagement and reflection, processes of emergence, which, according to Somerville (2007), are fundamental to the generation of new knowledge.

In an almost poetic space of echo and iteration, writing emerged not only as the central focus of the case of study, but also a key strategy in the research process. Writing-asa-method-of-inquiry is data generation, analysis and representation (Richardson, 1994). By researching through writing, new insights have emerged in this study. Though the broader notion of spatiality was held from the beginning, the process of writing supported the analysis and consequent 'emergence' of the different spatial relations.

Reflections, both informal and formal, during and at the end of each retreat, were analysed to find what makes these retreats supportive spaces for academics to engage in the scholarship of teaching and learning. Questions asked not only focused on what it is the academics planned and managed to achieve during the retreats, but also probed for insights into what it is about the retreats they find conducive or enabling in terms of their scholarship.

What emerged from the process of engagement was the identification of a range of conceptual 'threads', building on the theoretical 'warp and weft' of spatiality and sociality. It is recognised that what is studied does not exist within a vacuum, but is rather embedded within particular historical, economic, political, gendered, racialised, eco-socio-cultural moments in time. The experiences drawn on here offer insights into some of the 'threads' of a complex 'tapestry' of multiple interactions, iterations and ideas (Brooks, 2010). These 'threads' have been categorised within a broad spatial frame suggesting relational positioning: space within, space between and space beyond. It is recognised that these categories are 'false' in that such spaces are by no means discrete, but are entangled, ontologically enmeshed. However, for the purposes of this study, these categories help in 
offering a socio-spatial frame intended at developing an holistic characterisation of the context.

\section{Space Within}

The idea of 'space within' relates to a notion of space within the individual person: the intrapersonal. Reflections on the writing retreats revealed insights around one's state of mind, the enhanced ability to concentrate, to think deeply, to be creative and the consequent development of one's identity as an academic writer in the field of teaching and learning.

\section{State of Mind}

'The surrounding environment is superb and made a big impact on my state of mind'.

Retreats not only provide dedicated time and space for writing but also influenced the writers' mental space. Participants reflected on how the physical context of the retreats induced calm, relaxed, focused and creative engagement. They offered 'space both physical and mental to find a modus operandi that suits the mood/working style'.

\section{Concentration}

Academics are so used to having to multi-task, it is unusual to have an opportunity designed specifically to concentrate on just one activity:

'Even those of us who have been writing for many years struggle to find the space to focus and the inspiration and stimulation to write. And those of us who are stimulated find there is so much to write about we cannot get one thing finished before starting another and find ourselves spinning plates, hoping they won't be too outdated to serve up when we finally stop spinning them'.

The space of the writing retreat encourages an 'enforced' focus - concentration on what is meant to be an important and integral part of our professional lives as academics. The retreats offer space which is experienced as conducive to the intensive engagement required for the scholarship of teaching and learning:

'It was a very helpful time for focusing effort in a way that is hard to do while at work'.

'The isolated environment enabled me to focus on the task at hand. The peace and quiet helped me concentrate and focus'.

'Seeing other people working and listening to people discussing their challenges and victories enabled me to engage with my own work and concentrate for longer periods of time'. 


\section{Contemplation}

The process of writing is in itself a space of contemplation, a process of revealing thought and complexities. Writing supports and helps to articulate thinking, it is not necessary to always know what you are going to write but to use the process of writing to support the thinking:

'I actually enjoyed the process and the space to focus and reflect'.

Other aspects of the writing retreats are also conducive to contemplation. Participants found the natural, calm and peaceful surroundings a stimulant for deeper thought and engagement. The setting of the retreat is chosen with its 'promise' of peace and tranquility designed to aid contemplation. We also strongly encourage participants to take daily walks in the surrounding area and we schedule a group one every evening. Other contemplative activities include yoga at the bluff (a rocky area at the edge of the mountain) and walking the labyrinth, situated in the venue grounds.

Interestingly, much has been written about the benefit of labyrinth walks for contemplation and reflection. Labyrinths have been used historically for discovery and fulfilment, to relieve stress and to develop and sustain greater focus (Geurin, 2014). Having read this work just recently I am inspired to strongly encourage participants to walk the labyrinth, not just as a recreational activity but as a space of reflection and inspiration. Like mazes with no wrong turns, one just follows a single path which takes you to the centre and out again. It is easy to see how labyrinths can be used as 'tools... for introspection, reflection, decreasing anxiety and decreasing stress' (Dalley-Hewer, Opie and Knowles, 2015: 766), all very useful on a writing retreat.

\section{Creativity}

The retreats are designed, facilitated and experienced as spaces of calm and creation, an 'imaginative space' for writing (Grant and Knowles, 2000: 6).

'Having a sustained period in which to write enabled me to become creative'.

'The retreat was a wonderful creative space, free from major outside interruptions'.

As already mentioned, walking is always strongly encouraged on the retreats. The rationale for this was for a space of exercise and fresh air. However, in addition to a sense of wellness, research has demonstrated that walking also 'opens up the free flow of ideas', and is 'a simple and robust solution to the goals of increasing creativity' (Oppezzo and Schwartz, 2014: 1142).

\section{Space Between}

The idea of 'space between' relates to a notion of relation between people; the inter-personal. Threads of commitment, connection, collegiality, interaction, support and safety emerged in this space. 


\section{Commitment}

It is not easy for academics to set aside a period of four days to go away to focus on their writing. Usually arrangements must be made in order to make this happen, even if it is only the setting up of an out of office notice on one's email. Usually, though, it goes beyond this, especially for those who have families and departments to organise. The point is, that by participating in a retreat, one not only commits to devoting time to writing, but one also commits to one's community - both the communities you are retreating from (academic departments and families) and the community you are retreating to (the shared community of writing on retreat).

On applying to attend the retreat, participants are informed that they will need to focus on a piece of writing around teaching and learning which they will be asked to share in developing a bank of texts, which have been supported by attendance at the retreats. On the application form, the participants indicate what they will be focusing on at the retreat, and at the first session, where we all get together for a meeting, we make a commitment to what it is we are going to do at the retreat. At the end of the retreat we all reflect on what we managed to achieve and when the texts are finalised, participants share these with the facilitators to contribute to an ongoing collection of texts focused on the scholarship of teaching and learning.

\section{Connection}

While some of the participants chose to do their writing alone in the privacy of their own room, most of the participants chose to use the communal areas where they could work alone but in the company of others.

The retreat was recognised as a space to meet, connect and engage with academics from other disciplines. As Murray and Newton (2009: 550) suggest, the writing retreat may be viewed as 'a community of practice situated between multiple communities, crossing boundaries by including academics from different disciplines'.

'It was interesting and supportive to speak intermittently with different members of the Rhodes community and to be inspired by different disciplinary approaches'.

I really enjoyed spending time with colleagues from other departments, listening and learning more about what goes on in different spaces of the university. I feel less frustrated and alone in terms of my research and teaching, having spent time with others experiencing the same things'.

\section{Collegiality}

In contrast to the often competitive and individualistic spaces of the neoliberal university, the writing retreat is one which encourages a spirit of collegiality (Murray and Newton, 2009). Academics reflect on meeting, engaging and working with people they would normally not. The shared spaces and activities encourage a spirit of working together and support of each other, which not all academics are used to in their everyday academic work.

Academics appreciated 'inputs from other participants', 'interaction and updates over meals' and generally 'networking and engaging with people' from outside of their 
department. They enjoyed the 'friendly environment' and 'meeting other people'. They found participants to be very open and collegial:

'The collegiality and opportunity to interact with colleagues from other 'silos' in the university has been a great opportunity'.

\section{Interaction}

'Informative and supportive conversations with colleagues' over a meal, interactions in workshops, feedback on each other's writing and 'reporting' sessions, were all acknowledged to be useful in supporting processes of writing:

'All the peer interactions were very rewarding'.

'Talking to others during breaks helped with direction and structure'.

'Discussion over meal times where there was exchange of ideas was inspiring'.

The sharing of ideas, strategies, struggles and strengths in both formal and informal ways was clearly recognised as being of much support to the writers:

'The retreat was an amazing space to not only write, but to talk about writing'.

'I have benefitted enormously from the conversations and guidance to reading on teaching and education'.

'It was great to have facilitators who were unreservedly available and colleagues whose own experiences were availed without reservation as well'.

The participants also expressed appreciation of the informal spaces of support offered by colleagues over mealtimes, walks on the mountain paths, and glasses of wine in front of the fire in the evenings.

\section{Support}

The support of a 'writing community' such as that which develops at the writing retreats, generates strength to move forward in constructive and positive ways, as academic writers and scholars of teaching and learning. While the production of a piece of writing is clearly the ultimate intention, the focus at the retreat itself is on the process of scholarly engagement, in this case writing. Struggles and triumphs are articulated and strategies to support the development of writing are shared. Participants learn from, and support, each other. CHERTL facilitators, who have expertise they share, hold the process. Participants highlighted this latter point:

'The availability of CHERTL team members/staff to chat whenever you're not sure/feeling a mental block with your writing/thinking'. 
'Accessibility of CHERTL. Such prompt feedback'.

'Expert guidance and help at crucial points in the process that saved much time'.

'Feedback available at any time'.

Participants who sought help from the facilitators on the retreat found that the engagement they experienced not only helped them to appreciate their strengths as academic writers, but also guided them in ways they could build on to grow as more effective scholars of teaching and learning. Academics found that the feedback they received was often helpful, not only in giving them advice as to how to develop their competence in writing, but also in giving them greater confidence where it was lacking. They felt inspired to go away and implement new strategies they had learned and to develop their writing in response to the feedback offered. The retreats are thus regarded as spaces in which academics grow as scholars, learn new strategies and grow in confidence.

Participants clearly appreciated the explicit, built-in support offered by the members of CHERTL. As facilitators, CHERTL academics would read and offer 'immediate and constructive feedback' on individual texts, which the participants found useful. The facilitators also led workshops around topics which participants had identified would be helpful. These spaces were also found to be very supportive e.g. writing strategy workshop:

\section{'I learned and used some useful writing strategies suggested by my colleagues'.}

'Having discussions about writing strategies really helped'.

'Sharing experiences really motivated me. I hope to apply the strategies to my own writing'.

Such support happens alongside the sharing of insights and understandings by all participants. Academics found it reassuring to find that they were not alone in the struggles they experience with scholarly writing around teaching and learning.

\section{Safety}

It is in such spaces of collegiality and support that retreats can provide 'safe havens' (Knowles, 2014); spaces in which academics do not feel so vulnerable, or at least feel freer to share their struggles, admit to their weaknesses and feel comfortable to ask for help. While many academics may feel insecure and exposed when it comes to the scholarship of teaching and learning, in particular writing, the retreat offers a space of 'safety', a space where we can confront and share our vulnerabilities and explore ways in which we can address these:

'Lynn and Sioux [two of the CHERTL facilitators] both bring remarkable skills to these moments - intellectual and practical hospitality that quickly creates safe space'. 


\section{Space beyond}

The idea of 'space beyond' relates to a notion of space that extends beyond the individual, whether alone or together: the extra-personal. Conceptual 'threads' of structure and flexibility, disengagement and balance emerged in this space.

\section{Structure and Flexibility}

Many of the participants appreciated the balance created between structure and flexibility. A daily schedule, structured around meal times, framed a mixture of structured and unstructured writing time, workshops, spaces to talk and spaces of quiet:

'I liked the fact that there was no strict schedule or structure that you had to follow ...you could work in your own space at your own time, however, the option of a structured environment was also available'.

'I appreciate having a structured programme for the retreat'.

'I liked the fact that we could write anywhere and knowing we could arrange meetings with colleagues for support'.

Other participants noted with appreciation the 'informal format' of the retreat, 'the structure of writing and breaks with exercise in between' and 'space in the schedule to work in a personal/flexible way'.

\section{Disengagement}

Many of the participants spoke to the notion of disengagement (Murray, 2015). They spoke to a sense of physical and cognitive disengagement, of 'having space away from daily \#\%\&\%@ to think'. The retreat was regarded as 'a special time and place away from other tasks and distractions', where daily routines and demands at both work and home are left behind:

'Time out from my life and its distractions and meals being taken care of freed up valuable, focused time'.

Participants found the break from routine and 'being taken care of' refreshing. They enjoyed 'having uninterrupted time to think deeply' about their writing:

'a relaxed, private environment where thoughts and writing were uninterrupted'.

One or two participants also expressed a sense of emotional disengagement, describing a sense of 'not having to worry about anything'.

'The tranquility of having to work without the disturbance of everyday responsibilities'. 
While there was a social dimension to the retreat, there was a definite sense of a disengagement from others, a distancing of oneself from other people and demands they may normally make on your time, disengaging from emails, social media and other technological distractions, disengaging from all other tasks and focusing on writing alone.

Many of the participants spoke of 'time': having 'much needed time to think and write', having 'time to sit and just think'. As one participant pointed out, it is about 'setting explicit time aside' which makes it work. Time does not change; it is what you do with it that changes. While it is regarded as 'such a luxury to have quality time with no interruptions and distractions', it is carving out specific spaces of time for writing where one can disengage from other distractions, which helps substantially in getting it done.

'The space to sit, think, read and write without distraction has been an absolute gift!'

\section{Balance}

Participants appreciated the physical diversity of the retreat venue, affording access to 'different physical spaces to work' and enabling a balance of ways of working. Participants were able to work alone in their rooms, or in a range of indoor and outdoor spaces in the main venue. Both inside and outside spaces allowed for people to work alone or together. Very often academics chose to do both: to work alone, in the company of others.

\section{'Good balance of own work and sharing'.}

'I enjoyed the fact that we had other activities that are not only work. I enjoyed the yoga!'

The beauty, tranquility and serenity of the physical environment was recognised as being conducive to thought, reflection, creativity and writing. One participant also expressed how conducive the space was, not only to help her with her writing, but also in an holistic, embodied sense: to 'balance my body, mind and spirit'.

\section{Final Words}

A recent warning to the academy by Vale and Karataglidis (2016: np) points to the risk we are at of 'choking creativity and with it the profession itself' with the demand for publications. They highlight the importance and necessity of 'slow scholarship'. Such scholarship demands a deep engagement, which takes time, focusing in on processes of rich and rigorous research, echoed in approaches to, and the production of, academic writing. Fitting in such activities demands the making of particular spaces for ongoing and deep engagement. While ideally we need to find ways of integrating such work into our daily academic lives, it is clear that we need dedicated spaces, which support and encourage the development of such work. Well-organised writing retreats are proving to be just the kind of spaces academics need to make such work possible.

This paper has offered some insight into some of the dimensions making writing retreats spaces of great potential and possibility for the scholarship of teaching and learning. With the increasing demands on academics in their daily professional life, offering 
opportunities to attend such retreats needs to become the rule rather than the exception; retreats need to become part of 'business as usual'. At Rhodes University retreats are sometimes organised at departmental level, but financial support from the Teaching Development Grant has enabled us to extend this practice to a regular, multidisciplinary institutional space. Our research into this latter space demonstrates the value of such spaces, not only within (personal) but between (interpersonal) and beyond (extra-personal).

'Weaving' together personal reflections and scholarly work, this paper offers a 'tapestry' of meaning-making emerging through the sharing of reflections on the experience of engaging with writing retreats. Through such exchanges we have gained greater insight and further developed our understanding around ways to continue and further develop spaces for the support and development of the scholarship of teaching and learning, in this case specifically writing.

While the dimensions identified offer a clear picture of the constructive conditions afforded by the space of writing retreats, the identification of such dimensions can also offer us potentially new ways of thinking about how we can adapt our everyday academic lives. We need to consider how to work with the spaces within, between and beyond in ways which will make the everyday academic spaces more conducive to the scholarly engagement with teaching and learning, particularly writing.

\section{Acknowledgement}

This paper is written in part with the support of funding from the Department of Higher Education National Collaborative Teaching Development Grant: The improvement of teaching and learning in South African universities through researching and evaluating TDG projects in the First Year Experience (FYE) initiatives, Tutorials, Mentoring and Writing Retreats.

Sue Southwood is a Development Practitioner based at the Centre of Higher Education, Research, Teaching and Learning (CHERTL), Rhodes University in Grahamstown, South Africa. She has worked in the field of educational development in different parts of the world for thirty years. She has worked at all levels of the education system, the most part based in the arena of Higher Education. Her work focuses on collaborative, dialogic and appreciative approaches to development. Underpinning such work are theoretical ideas related to space, relationality and emergence.

\section{References}

Aitchison, C. \& Guerin, C. 2014. Writing groups, pedagogy, theory and practice: An introduction. In Aitchison, C. \& Guerin, C. Writing groups for doctoral education and beyond: Innovations in practice and theory. Abingdon: Routledge.

Arias, S. 2010. Rethinking space: An outsider's view of the spatial turn. GeoJournal, 75: 29. DOI: $10.1007 / \mathrm{s} 10708-010-9339-9$.

Baerenholdt, J.O. \& Simonsen, K. 2004. Space odysseys: Spatiality and social relations in the $21^{\text {st }}$ century. Aldershot: Ashgate Publishing Ltd. 
Benvenuti, S., Castle, J. \& Keane. M. 2013. Writing retreats in response to the incessant demands' of the university. 4th World Conference on Learning, Teaching and Educational Leadership. October 27-29, 2013. Barcelona, Spain. Available online at www.sciencedirect.com.

Bronack, S., Sanders, R., Cheney, A., Riedl, R., Tashner, J. \& Matzen, N. 2008. Presence pedagogy: Teaching and learning in a $3 \mathrm{D}$ virtual immersive world. International Journal of Teaching and Learning in Higher Education, 20(1): 5969.http://www.isetl.org/ijtlhe/ ISSN 1812-9129.

Brooks, J.G. 2010. Teaching like a mountain: Toward a poetic pedagogy of presence in the midst of exposure. Unpublished doctoral dissertation, University of Pittsburgh.

Casey, B., Baron, C. \& Gordon, E. 2013. Reflections on an in-house academic writing retreat. Journal of Teaching and Learning in Higher Education, 5(1): 1041-1044.

Castle, J. \& Keane, M. 2016. Five writing development strategies to help academics flourish as writers. South African Journal of Higher Education, 30(6): 73-93.

DOI: $10.20853 / 30-6-721$.

Dalley-Hewer, J., Opie, J. \& Knowles, N. 2015. A creative alternative to reflective writing promoting skills of reflection through walking a labyrinth. Physiotherapy, 101(1): 766767.

Grant, B. 2006. Writing in the company of other women: Exceeding the boundaries. Studies in Higher Education, 31(4): 483-495.

Grant, B., \& Knowles, S. 2000. Flights of imagination: Academic writers be(com)ing writers. International Journal for Academic Development, 5(1): 6-19.

Guerin, C. 2014. The Power of Walking. Doctoral Writing SIG. https://doctoralwriting.wordpress.com/2014/10/24/the-power-of-walking/ (Accessed 1 August 2016).

Kemmis, S. 2005. Knowing practice: Searching for saliences, Pedagogy, Culture and Society, 13(3): 391-427.

Knowles, S. 2014. Writers in retreat: Conflicted knowledge workers, shifting identities and changing relations in the new enterprise university. Academic Identities Conference: Edith Cowan University, Australia. http://www.ee.ucl.ac.uk/ mflanaga/abstracts/AIC050.pdf (Accessed 1 August 2016).

Kümin, B. \& Usborne, C. 2013. At home and in the workplace: A historical introduction to the 'spatial turn'. History and Theory, 52: 305-318.

Lee, A. \& Boud, D. 2003. Writing groups, change and academic identity: Research development as local practice. Studies in Higher Education, 28(2): 187-200.

Mbembe, A. 2015. Decolonising knowledge and the question of the archive. Text for public lectures given at WISER, University of Witwatersrand.

McGrail, M.R., Rickard, C. M. \& Jones, R. 2006. Publish or perish: A systematic review of interventions to increase academic publication rates. Higher Education Research and Development, 25(1): 19-35.

Moore, S. 2003. Writers' retreats for academics: Exploring and increasing the motivation to write. Journal of Further and Higher Education, 27(3): 333-342. 
Moore, S., Murphy, M. \& Murray, M. 2010. Increasing academic output and supporting equality of career opportunity in universities: Can writers' retreats play a role? The Journal of Faculty Development, 24(3): 21-30.

Murray, R. 2015. Writing in social spaces. A social processes approach to academic writing. SRHE. London: Routledge.

Murray, R. \& Newton, M. 2009. Writing retreat as structured intervention: Margin or mainstream? Higher Education Research and Development, 28(5): 541-553. DOI: 10.1080/07294360903154126.

Oppezzo, M. \& Schwartz, D. L. 2014. Give your ideas some legs: The positive effect of walking on creative thinking. Journal of Experimental Psychology: Learning, Memory, and Cognition, 40(4): 1142-1152.

Richardson, L. 1994. Writing: A method of inquiry. In Denzin, N. \& Lincoln, Y. (eds.) Handbook of qualitative research. Thousand Oaks: Sage Publications.

Schatzki, T. 2002. The site of the social. A philosophical exploration of the constitution of social life and change. University Park: The Pennsylvania State University Press.

Somerville, M.J. 2007. Postmodern emergence. International Journal of Qualitative Studies in Education, 20(2): 225-243.

Vale, P. \& Karataglidis, S. 2016. Pressure to publish is choking the academic profession. The Conversation: Africa. July 6, 2016. http://theconversation.com/pressure-topublish-is-choking-the-academic-profession-62060 (Accessed 1 August 2016)

Vygotsky, L.S. 1978. Mind in society: The development of higher psychological processes. Cambridge, MA: Harvard University Press.

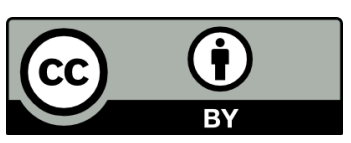

This publication is covered by a Creative Commons Attribution 4.0 International license. For further information please see: http://creativecommons.org/licenses/by/4.0/. 